\title{
vorwortdes sammlers
}

Die Sammlung verdankt ihre Entftehung einer Guregung von Gerrn prof. D. Rudolf Otto, der ihr auth den Mamen gab. Jlpre praktijne Ausfilhrumg wurde oura die selbitlofigkeit, mit der herr prof. D. Griedria ltiebergall leine Bibliofląh jur Derfilgung ftellte, ermögliat. Danh geblihrt aud ben Gerren Gutoren uns verlegern, die grofmilitig ihre werke in den Dientt der allgemeinheit ftellten. Denn das will die poitille tun: fie will dienen, Jem Ginjelnen uno der Gemeinde. Mit Dank wiro aud hier des verlegers, Gerrn Dr. b. c. AIfred Cöpelmann, gedaht flir feinte Bereitwilligkeit ju den manącrlei boriłlägen.

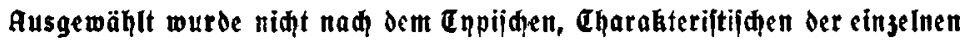
prediger. Dielmehr gab die predigtge wa It, dic $\mathbb{E}$ indrus ma Des wortes auf uns beute den ausidjlag. Die predigten find fo gut wie Jurḑweg niąt in Originallänge wiedergegeben, fondern es hat auh̆ im cin: jelnen cine Auswahl ftattgefunden. wenn der sejer nod feḥt viel Gutes und wertoolles vermift, fo ift das of $t$ auf mande rein äuperliąe saqwie:

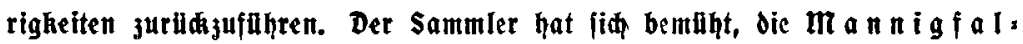
tigkeft der predigtitimmen aus dem ganzen Sauf der Jahrhunderte der фriftliden Kirde, foweit fie lebendig find, in unjere 3eit rufen ju laffen. So werden wir uns nidgt nur des Reidgtums, fondern vor allem der Katholi: cität, der Ul niverfalität der Kir qe bewuft. Mögen wir fo wieder fllhibar lebendig erfahren und lernen, was die "Kirdqe" ift. Doh möge man jebes Stifa lejen und hören unter dent e o a die evangelijh̨en eöne in jedem herausklingen hören und jedes nehmen als eingeordnet und pelber wieder herausklingend aus dem evangelifden Ganjen der poftille.

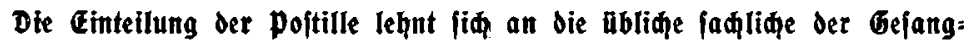
bihder an. So ijt auf dieje weife die benu bung oes Gejangbuds leidht gemaht und wird auberdent nod unterfinjt ourd Dorfaläge (aud für Chorgebete) in Anhang. Andrerieits ijt ourd defe Einteilung ood aud oie

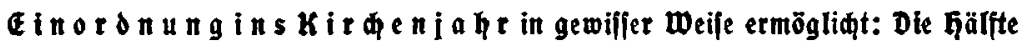
der Crinitatisjeit ift ftarh und breit bedaht dura den kreis der Stimmen, die ben 


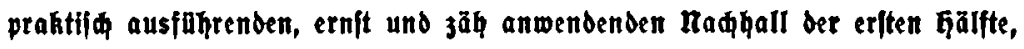
Der Seier ber Chriftusoffenbarung, bringen: Anbetung Gottes, Chriltenleben vor Gott und in der welt, Cod und Ewigkeit. Det famalgegebene fefthreis bant leiht aus ber falle vorwegnehmen, was in ihn paft. Im abrigen lit in Arhang eine năher eingehende Cinordnung in $\mathfrak{B}$. Otto's "Jaht bet Kirde" gegeben. - aberiariften und Bibelitellen lind in ber mehrzahl neu gegeben, da durh die ftarke kärjung die vorhandenen niat mehr fo ganj jutreffend waren.

Unter welhen Sinn julegt die polttlle geftelit wirb, fagt das vorangeftellte wort der Ģeiligen Sqgrift.

marbutg a. $\boldsymbol{\Sigma}$. 6. p.x $\mathbf{B}$. 